\title{
Robust transformation procedure for the production of transgenic farmer-preferred cassava landraces
}

Ima M Zainuddin, Kim Schlegel, Wilhelm Gruissem and Hervé Vanderschuren*

\begin{abstract}
Recent progress in cassava transformation has allowed the robust production of transgenic cassava even under suboptimal plant tissue culture conditions. The transformation protocol has so far been used mostly for the cassava model cultivar 60444 because of its good regeneration capacity of embryogenic tissues. However, for deployment and adoption of transgenic cassava in the field it is important to develop robust transformation methods for farmer- and industry-preferred landraces and cultivars. Because dynamics of multiplication and regeneration of embryogenic tissues differ between cassava genotypes, it was necessary to adapt the efficient cv. 60444 transformation protocol to genotypes that are more recalcitrant to transformation. Here we demonstrate that an improved cassava transformation protocol for cv. 60444 could be successfully modified for production of transgenic farmer-preferred cassava landraces. The modified transformation method reports on procedures for optimization and is likely transferable to other cassava genotypes reportedly recalcitrant to transformation provided production of high quality FEC. Because the three farmer-preferred cassava landraces selected in this study have been identified as resistant or tolerant to cassava mosaic disease (CMD), the adapted protocol will be essential to mobilize improved traits into cassava genotypes suitable for regions where CMD limits production.
\end{abstract}

Keywords: Cassava, Tropical crop, Genetic transformation, Somatic embryogenesis, Agrobacterium, Farmer-preferred landraces

\section{Introduction}

Cassava is the staple food for nearly a billion people in 105 countries [1]. Because of its resilience and capacity to grow on marginal lands, the importance of cassava cultivation in farming systems affected by climate change is expected to increase in the future [2]. The use of cassava as energy crop also contributes to its increasing production acreage in tropical countries [3,4]. However, the lack of resistance genes in the available germplasm, high heterozygosity, allopolyploidy, low fertility, and unsynchronized flowering make cassava improvement by conventional breeding a long and tedious process $[5,6]$. Therefore cassava genetic transformation has emerged as a valuable alternative and complementary approach to improve cassava $[7,8]$. Several protocols

\footnotetext{
* Correspondence: hvanderschuren@ethz.ch

Department of Biology, Plant Biotechnology, ETH Zurich-LFW E56.1, Universitaetstrasse 2, 8092, Zurich, Switzerland
}

using either cotyledons or embryogenic cultures as target tissues and particle bombardment or Agrobacteriummediated transformation procedures have been reported in the literature [8]. However the use of embryogenic tissues (i.e. friable embryogenic callus, FEC) in combination with Agrobacterium-mediated transformation has become the favoured method because of its higher efficiency compared to the cotyledon-based protocol [9-13]. Despite this progress cassava remains difficult to transform partly as the result of low transformation and regeneration frequencies. The Agrobacterium-FEC system is also unstable and in some conditions produces highly variable numbers of transgenic events [12]. As a consequence, cassava transformation requires well-trained tissue culture specialists, substantial amounts of plant material and repeated transformation cycles to generate a sufficient number of independent transgenic lines for research and product development. The instability of the transformation system renders the establishment of

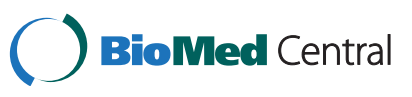

(c) 2012 Zainuddin et al.; licensee BioMed Central Ltd. This is an Open Access article distributed under the terms of the Creative Commons Attribution License (http://creativecommons.org/licenses/by/2.0), which permits unrestricted use, distribution, and reproduction in any medium, provided the original work is properly cited. 
cassava transformation technology under less favourable conditions more challenging [14-16]. Recent progress in the optimization of the transformation protocol has substantially increased efficiency and robustness $[17,18]$. The improved transformation protocol was subsequently established in laboratories located in Africa based on hands-on workshops and training of local scientists $[15,16]$.

The majority of transgenic cassava reports have been based on the transformation of the model cultivar 60444 (previously referred to as TMS 60444) [8]. While proofof-concept is possible with the model cultivar, the importance of transforming farmer- and industry-preferred cassava cultivars is essential for the adoption of transgenic cassava $[7,15,16]$. Because transgenic strategies to improve cassava are now being evaluated in the field $[9,12,13]$ it is also important to assess the technology in cassava genotypes adapted to the respective field environments. Locally adapted cultivars and landraces have often been selected and adopted by farmers because of particular improved traits [19]. Production of transgenic events in those selected genotypes offer the possibility to rapidly stack improved traits. Improvement of farmerpreferred genotypes using Agrobacterium-mediated transformation of FEC, however, has been limited by the difficulty of generating plant tissue suitable for transformation, the low regeneration efficiency of FEC, and the time necessary for embryo maturation following their co-cultivation with Agrobacterium [8]. In particular, FEC initiation and time to regeneration are genotype dependent $[20,21]$.

Here we describe a modified and efficient method for transformation of three farmer-preferred cassava landraces that were selected based on their virus resistance $[19,22]$ as well as preferential and extensive use in Africa. Production of tissues suitable for transformation were generated and tested for regeneration. Because their multiplication and regeneration dynamics differed from cv. 60444, a modified transformation protocol was developed.

\section{Materials \\ Reagents}

Plant material

Shoot cultures of cv. 60444 and three farmer-preferred cassava landraces ( $2^{\text {nd }}$ Agric (TME3), Oko-iyawo (TME7), and Abbey-ife (TME14)) [19] were obtained from the ETH Zurich and International Institute of Tropical Agriculture (IITA, Nigeria) in vitro cassava germplasm collections.

\section{Bacteria}

Agrobacterium tumefaciens LBA4404 harboring CAMBIA 1301 plasmid (GeneBank AF234297) which contains the hptII gene for resistance to hygromycin and the gusA reporter gene driven by the constitutive $35 \mathrm{~S}$ promoter.

\section{Media}

- CBM (basic shoot culture medium), for propagation of in vitro plantlets: $1 \times$ MS salts with vitamins, $2 \mu \mathrm{M}$ $\mathrm{CuSO}_{4}, 2 \%$ sucrose, $0.3 \%$ Gelrite, $\mathrm{pH}$ 5.8, autoclaved

- CAM (axillary bud enlargement medium), for induction of axillary buds: $1 \times$ MS salts with vitamins, $2 \mu \mathrm{M} \mathrm{CuSO}_{4}, 10 \mathrm{mg} / \mathrm{l} \mathrm{BAP,} 2 \%$ sucrose, $0.8 \%$ Noble agar, pH 5.8, autoclaved

- CEM (shoot elongation medium) for shoot elongation: 1x MS salts with vitamins, $2 \mu \mathrm{M} \mathrm{CuSO}_{4}, 0.4 \mathrm{mg} / \mathrm{l}$ BAP, 2\% sucrose, 0.8\% Noble agar, pH 5.8, autoclaved

- CIM (somatic embryo induction medium) for induction of somatic embryos: $1 \times$ MS salts with vitamins, $2 \mathrm{uM} \mathrm{CuSO}$, $12 \mathrm{mg} / \mathrm{l}$ picloram, $2 \%$ sucrose, $0.8 \%$ Noble agar, pH 5.8, autoclaved

- GD (friable embryogenic callus medium) for induction and propagation of FEC: 1x GD salts with vitamins, $12 \mathrm{mg} / \mathrm{l}$ picloram, $2 \%$ sucrose, $0.8 \%$ Noble agar, pH 5.8, autoclaved

- GD (friable embryogenic callus medium) liquid medium for dilution of bacteria and FEC washing steps: $1 \times$ GD salts with vitamins, $12 \mathrm{mg} / \mathrm{l}$ picloram, $2 \%$ sucrose, $\mathrm{pH} 5.8$, autoclaved

- MSN (somatic embryo emerging medium) for regeneration of embryos: $1 \times$ MS salts with vitamins, $1 \mathrm{mg} / \mathrm{l} \mathrm{NAA,} \mathrm{2 \%} \mathrm{sucrose,} \mathrm{0.8 \%} \mathrm{Noble} \mathrm{agar,} \mathrm{pH} \mathrm{5.8,}$ autoclaved

- YEB (yeast extract broth) solid medium for Agrobacterium selection: $1 \mathrm{~g} / \mathrm{l} \mathrm{Bacto}^{\mathrm{TM}}$ yeast extract, $5 \mathrm{~g} /$ Bacto $^{\mathrm{TM}}$ beef extract, $5 \mathrm{~g} / \mathrm{l} \mathrm{Bacto}^{\mathrm{TM}}$ peptone, 5 g/l sucrose, $1.5 \%$ Bacto $^{\mathrm{TM}}$ agar, $\mathrm{pH} 7.2$, autoclaved

- YEB (yeast extract broth) liquid medium for Agrobacterium culture: $1 \mathrm{~g} / \mathrm{l} \mathrm{Bacto}^{\mathrm{TM}}$ yeast extract, $5 \mathrm{~g} /$ Bacto $^{\mathrm{TM}}$ beef extract, $5 \mathrm{~g} / \mathrm{l} \mathrm{Bacto}^{\mathrm{TM}}$ peptone, 5 g/l sucrose, pH 7.2, autoclaved. Supplemented with $\mathrm{MgSO}_{4}$ sterile solution (2 $\mathrm{mM}$ final concentration)

\section{Other chemicals}

- Antibiotics for bacterial selection: kanamycin $50 \mathrm{mg} / \mathrm{mL}$ solution, rifampicin $25 \mathrm{mg} / \mathrm{mL}$ solution, and streptomycin $100 \mathrm{mg} / \mathrm{mL}$ solution

- Antibiotics for prevention of bacterial growth: carbenicillin $500 \mathrm{mg} / \mathrm{mL}$ solution.

- Antibiotics for selection of transformed cassava FEC and rooting test of transgenic cassava plantlets: hygromycin $15 \mathrm{mg} / \mathrm{mL}$ solution.

- Acetosyringone $200 \mathrm{mM}$ solution

- GUS reaction buffer: $10 \mathrm{mM}$ Tris (pH7.2), $50 \mathrm{mM}$ $\mathrm{NaCl}, 0.1 \%$ Triton X-100, and $0.5 \mathrm{mg} / \mathrm{mL}$ 5-bromo4-chloro-3-indolyl glucuronide

- Reagents for Southern blot: HindIII and PstI restriction enzymes, $1 \%$ agarose gel, Hybond-N+ 
membrane (GE Healthcare), DNA probe (hptII DNA probe labeled with the DIG labelling $\operatorname{mix}$ (Roche))

\section{Plasticware \& other consumables}

- Sterile plastic Petri dishes, $90 \mathrm{~mm}$

- Plastic mesh $100 \mu \mathrm{m}$, sterile

- Pipettes $25 \mathrm{~mL}$, sterile

- Sterile jars

- $15 \mathrm{~mL}$ and $50 \mathrm{~mL}$ sterile disposable tubes

- Eppendorf tubes (1.5 mL)

- Parafilm

- Sterile disposable syringe filters $(0.22 \mu \mathrm{m})$

- Aluminium foil

- Disposable syringes (10 mL)

- Sterile, disposable $1 \mathrm{~mL}$ tips

- Films (Kodak BioMax Light Film)

\section{Equipments}

- Autoclave

- $\mathrm{pH}$ meter

- Precision balance

- Centrifuge for $50 \mathrm{~mL}$ tubes

- Shaker

- Controlled environment chamber/room $\left(28^{\circ} \mathrm{C}, 16 \mathrm{~h}\right.$ light $/ 8 \mathrm{~h}$ dark $)$

- Controlled environment chamber/room $\left(24^{\circ} \mathrm{C}, 16 \mathrm{~h}\right.$ light $/ 8 \mathrm{~h}$ dark $)$

- Pipette aid

- Laminar flow hood with Bunsen burner

- Fridge $\left(4^{\circ} \mathrm{C}\right)$ and freezer $\left(-20^{\circ} \mathrm{C}\right)$

- Spatula, scalpel, and forceps

- Binocular microscope

- Inoculation loops

- Incubator-shaker $\left(28^{\circ} \mathrm{C}\right)$

- Spectrophotometer

- $1 \mathrm{~mL}$ disposable cuvettes

- Magnetic stirring bars

- Vortexer
- Micropipette

- PCR machine

- UV - crosslinker (BIO-LINK ${ }^{\mathrm{m}}$ )

- Processor (Agfa Curix 60)

\section{Protocols \\ Production of somatic embryos from cv. 60444, $2^{\text {nd }}$ Agric, Oko-iyawo, and Abbey-ife}

1. Take 5-10 mm long stem cuttings from 4-week-old in vitro plantlets of selected cassava cultivars and place them horizontally on Petri dishes containing CAM for $2-4$ days at $28^{\circ} \mathrm{C}$ in the dark.

2. Remove the enlarged axillary buds from the nodal explants with sterile syringe needles under a binocular microscope and transfer them to Petri dishes containing CIM. Keep them for two weeks at $28^{\circ} \mathrm{C}$ in the dark.

3. Subculture the developing embryos (Figure 1) with sterile syringe needles. Use a binocular microscope to remove callus developing around the embryos. Place the embryos on fresh CIM at $28^{\circ} \mathrm{C}$ in the dark. Do this step at two-week intervals for multiplication of the embryos and initiation of cyclic secondary somatic embryogenesis.

NOTE: Cyclic embryogenesis is a routine method of de novo plant regeneration in vitro and is particularly adequate to provide a constant source of pure embryo clusters necessary for the induction of friable embryogenic callus (FEC). Four cycles on CIM usually generate sufficient quantities of pure secondary somatic embryos required for FEC induction of all selected landraces.

\section{Production and proliferation of FEC}

This step is a key parameter of the protocol because FEC production as well as their capacity to proliferate and regenerate are strongly genotype-dependent $[16,20,23]$.
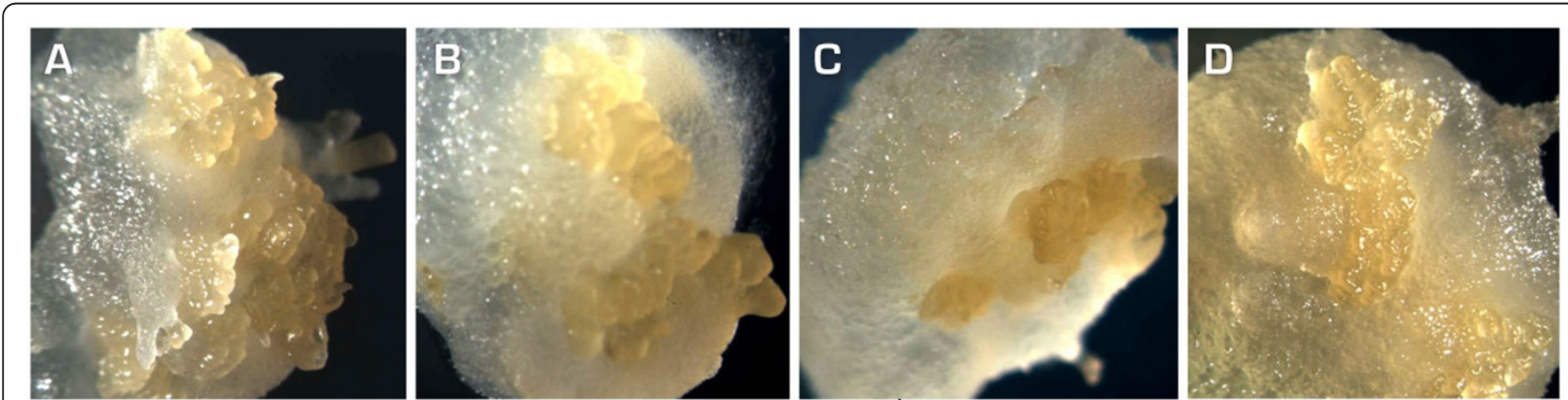

Figure 1 Primary somatic embryos of cassava genotypes: A. cv. 60444, B. $2^{\text {nd }}$ Agric, C. Oko-iyawo, D. Abbey-ife. 
Table 1 FEC induction results of the selected cassava genotypes

\begin{tabular}{lccc}
\hline Name & $\begin{array}{c}\text { Somatic Embryos } \\
\text { (clusters) }\end{array}$ & $\begin{array}{c}\text { FEC } \\
\text { (clumps) }\end{array}$ & $\begin{array}{c}\text { Percentage } \\
\text { (\%) }\end{array}$ \\
\hline cv. 60444 & 168 & 128 & 76 \\
2nd Agric & 244 & 24 & 11 \\
Oko-iyawo & 168 & 32 & 19 \\
Abbey-ife & 232 & 24 & 10
\end{tabular}

Each plate contains 9 clusters of somatic embryo or 9 clumps of FEC.

1. Transfer an equal amount of secondary embryos from each genotype to GD medium and incubate them at $28^{\circ} \mathrm{C}$ in the dark. Check the plates visually under a binocular microscope to identify the developing FEC. Do this step every week (up to four weeks) after transfer to GD medium since FEC initiation and development is genotype-dependent. OUR RESULTS: Table 1 shows the percentage of FEC initiated on GD medium for the selected cassava landraces. Even though high quality secondary somatic embryos were used for all farmer-preferred landraces, their potential for FEC generation was significantly lower when compared to cv. 60444 .

2. Subculture the embryos to fresh GD at three weeks interval to purify and multiply high quality FEC. Multiply the FEC over 2-3 cycles on GD medium in the dark at $28^{\circ} \mathrm{C}$ to obtain high quality and pure FEC (Figure 2).

3. To determine the optimal light regime, incubate the high quality FEC in $16 \mathrm{~h}$ photoperiod or in the dark (see next steps).

4. Measure their weight increase after 2-3 weeks which corresponds to the typical proliferation time for multiplication of cv. 60444 FEC. OUR RESULTS: In the light FEC from $2^{\text {nd }}$ Agric and Oko-iyawo landraces showed a higher weight increase than FEC from cv. 60444 (Figure 3). While production of FEC differed substantially between cv. 60444 and the farmer-preferred landraces (Table 1), selection of high quality FEC could overcome those limitations by rapid proliferation on GD medium.
The proliferation of FEC in the dark was slower than in the light.

5. Transfer FEC to a low auxin medium for maturation (i.e. somatic embryo emerging medium, MSN).

6. Count the number of emerging embryo per FEC clump every week (up to 5-6 weeks).

7. Compare the proliferation and regeneration rate of the selected landraces between the light and dark regime to determine the influence of light regime on FEC regeneration capacity. OUR RESULTS: The dark regime for FEC multiplication did have a negative effect on cv. 60444 embryo maturation potential. On the contrary $2^{\text {nd }}$ Agric FEC regenerated a significantly higher number of maturing embryos when initially proliferated in the dark (Figure 4). Because of the positive or neutral effect of FEC proliferation in the dark on the embryo regeneration rate for the selected farmer-preferred landraces (Figure 4), all selective steps on FEC proliferation media were performed in the dark.

\section{Agrobacterium-mediated transformation \\ Preparation of Agrobacterium culture for inoculation}

1. Inoculate a single colony of $A$. Tumefaciens LBA4404 harboring pCAMBIA1301 into $5 \mathrm{~mL}$ of YEB liquid medium containing the following antibiotics: kanamycin $50 \mathrm{mg} / \mathrm{L}$, rifampicin $50 \mathrm{mg} / \mathrm{L}$ and streptomycin $100 \mathrm{mg} / \mathrm{L}$. Keep the culture at $28^{\circ} \mathrm{C}$ with $200 \mathrm{rpm}$ agitation overnight.

2. Take $1 \mathrm{~mL}$ of the overnight culture to inoculate $25 \mathrm{~mL}$ of YEB liquid medium supplemented with the aforementioned antibiotics in $250 \mathrm{~mL}$ flask under the same growth conditions.

3. After reaching an $\mathrm{OD}_{600}$ of 0.7-1.0, pellet the bacteria by centrifugation in $50 \mathrm{~mL}$ tubes at $5000 \mathrm{rpm}$ for $10 \mathrm{~min}$.

4. Remove the supernatant and resuspend the bacteria pellet in GD liquid medium to remove antibiotics. Centrifuge the bacteria suspension at $5000 \mathrm{rpm}$ for $10 \mathrm{~min}$.
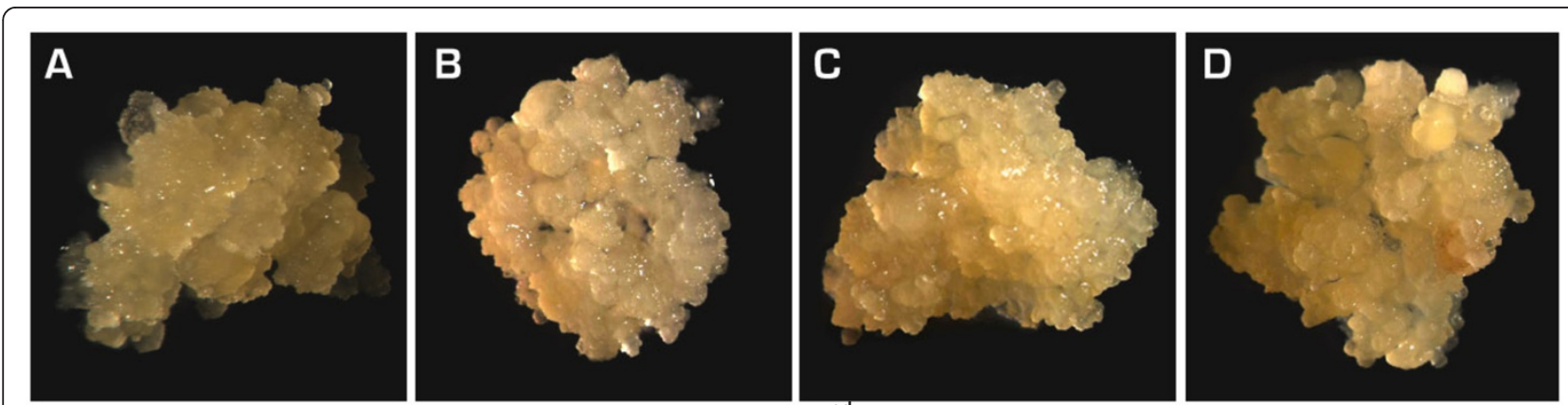

Figure 2 Proliferating FEC from cassava genotypes: (A) cv. 60444, (B) $2^{\text {nd }}$ Agric, (C) Oko-iyawo, (D) Abbey-ife. 


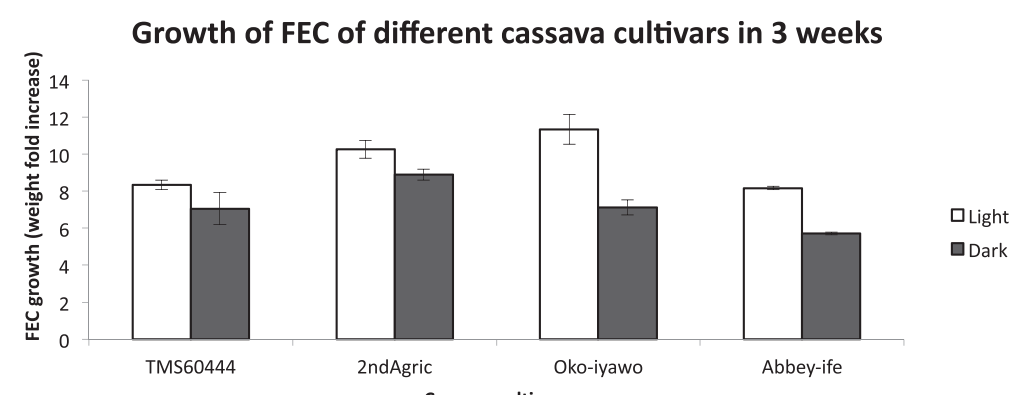

Figure 3 FEC growth after three weeks on GD medium. Each value represents the mean \pm SE of two plates, each with 4 FEC clumps.

5. Remove the supernatant and resuspend the bacteria pellet in GD liquid medium to a final $\mathrm{OD}_{600}$ of 0.5 .

6. Add acetosyringone to the Agrobacterium culture to a final concentration of $200 \mu \mathrm{M}$.

7. Shake the cultures at $50 \mathrm{rpm}$ for $45 \mathrm{~min}$ at room temperature.

\section{Agrobacterium inoculation and co-cultivation of FEC}

1. Drop the bacteria suspension with $1 \mathrm{~mL}$ pipette on FEC clumps until each clump becomes wet and remove the excess of bacteria suspension. Seal the Petri dishes and incubate at $22-23^{\circ} \mathrm{C}$ for 3 days under the optimal light/dark regime (16 h photoperiod for the cv. 60444 FEC and in the dark for the farmerpreferred landraces).

2. Scrape the inoculated FEC using sterile forceps and place them in $25 \mathrm{~mL}$ GD liquid medium containing carbenicillin $500 \mathrm{mg} / \mathrm{L}$. Use sterile $50 \mathrm{~mL}$ tubes for this step.

3. Gently vortex the suspension for $5-10 \mathrm{~s}$ and then allow the FEC to pellet.

4. Remove the supernatant GD medium and repeat the washing step until the GD medium becomes clear and transparent. It usually requires 4-5 washing steps.

5. Resuspend the cleaned FEC in GD solution with a $25 \mathrm{~mL}$ sterile pipet and spread them evenly on a sterile $100 \mu \mathrm{m}$ nylon mesh.
6. Transfer the mesh with the FEC layer on sterile filter paper to remove excess GD medium.

7. Place the mesh with FEC on GD plate containing carbenicillin $250 \mathrm{mg} / \mathrm{L}$ for $3-4$ days at $28^{\circ} \mathrm{C}$ under optimal light/dark regime ( $16 \mathrm{~h}$ photoperiod for the cv. 60444 FEC and in the dark for the farmerpreferred landraces).

\section{Gradual selection of transformed FEC}

By comparing the performance of two different treatments, single-step (SS) gradual selection, which corresponds to the procedure previously described by Bull and colleagues [17], and double-step (DS) gradual selection in which the time on gradual selection was doubled, we showed that doubling the time of recovery and proliferation substantially increased the number of maturing embryos on MSN medium in the following regeneration steps (Table 2). Hence we outlined below the procedure of DS gradual selection for the selected cassava landraces:

1. Transfer the mesh with FEC to GD plates supplemented with carbenicillin $250 \mathrm{mg} / \mathrm{L}$ and hygromycin $5 \mathrm{mg} / \mathrm{L}$. Place them in the dark at $28^{\circ} \mathrm{C}$ for 2 weeks with medium replenishment every week.

2. Transfer the mesh with FEC to GD plates supplemented with carbenicillin $250 \mathrm{mg} / \mathrm{L}$ and hygromycin $8 \mathrm{mg} / \mathrm{L}$. Place them in the dark at $28^{\circ} \mathrm{C}$ for 2 weeks with medium replenishment every week.

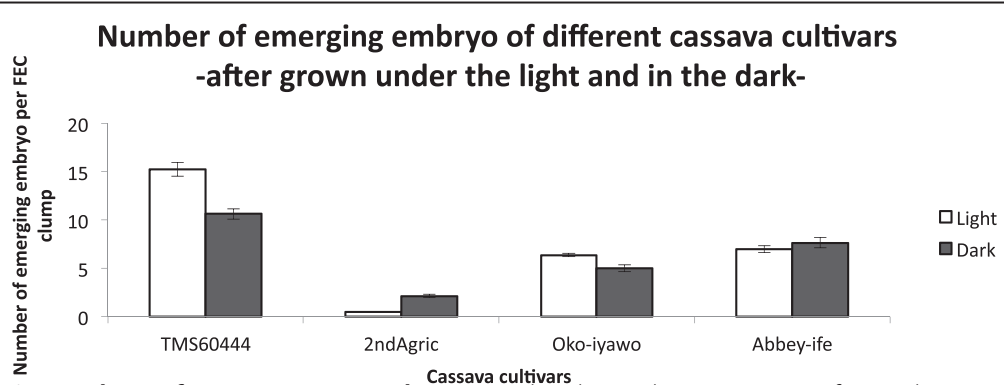

Figure 4 Number of emerging embryos from cassava FEC clumps. Each value is the mean \pm SE of two plates, each with 4 clumps of FEC. 
Table 2 Assessment of single-step (SS) and double-step (DS) selection procedure using the Agrobacterium-FEC transformation procedure with the selected genotypes

\begin{tabular}{lccc}
\hline Genotype & Procedure & $\begin{array}{c}\text { Cumulative } \\
\text { number }\end{array}$ & $\begin{array}{c}\text { Amount of FEC of } \\
\text { maturing embryos (clumps) }\end{array}$ \\
\hline CV. 60444 & SS & 18 & 58 \\
CV. 60444 & DS & 18 & 122 \\
2nd Agric & SS & 18 & 8 \\
2nd Agric & DS & 18 & 32 \\
Oko-iyawo & SS & 18 & 23 \\
Oko-iyawo & DS & 18 & 57 \\
\hline
\end{tabular}

3. Transfer the mesh with FEC to GD plates supplemented with carbenicillin $250 \mathrm{mg} / \mathrm{L}$ and hygromycin $15 \mathrm{mg} / \mathrm{L}$. Place them in the dark at $28^{\circ} \mathrm{C}$ for 2 weeks with medium replenishment every week.

\section{Selection and regeneration of transformed plantlets}

1. Transfer the mesh with FEC to MSN plates supplemented with carbenicillin $250 \mathrm{mg} / \mathrm{L}$ and hygromycin $15 \mathrm{mg} / \mathrm{L}$. Incubate at $28^{\circ} \mathrm{C}$ in $16 \mathrm{~h}$ photoperiod for 7-10 days.

2. Repeat step 1 up to six times. Small, greenish tubelike structures will start appearing after 2-4 cycles on MSN. Retain them on the mesh until development of green cotyledons.

3. Use sterile forceps or syringe needles under the binocular microscope to transfer the matured embryos with expanded green cotyledons to CEM solid medium supplemented with carbenicillin $100 \mathrm{mg} / \mathrm{L}$.

\section{Histochemical GUS assay}

To determine the percentage of transgenic maturing embryos appearing on the regeneration medium, embryos can be selected and tested using the GUS assay by following the steps as earlier described [18]:

1. Immerse the randomly selected matured embryos in GUS reaction buffer.

2. Incubate at $37^{\circ} \mathrm{C}$ overnight.

3. Remove the GUS buffer and wash the embryos with $70 \%$ ethanol solution.
OUR RESULTS: The percentage of GUS positive embryos varied between the selected landraces (Table 3). For all selected landraces more than half of the embryos were GUS positive.

\section{Rooting test}

This procedure is an easy method for rapid and reliable screening of transgenic cassava lines [17,24]:

1. Cut the shoots elongating on CEM and transfer them to CBM jars supplemented with carbenicillin $50 \mathrm{mg} / \mathrm{L}$ and hygromycin $10 \mathrm{mg} / \mathrm{L}$. Use the plantlets of non transformed wild-type cassava as negative control.

2. Maintain the plantlets under $16 \mathrm{~h}$ photoperiod at $28^{\circ} \mathrm{C}$.

3. Check the appearance of adventitious roots on cuttings at 2 weeks after planting. Transgenic shoots develop adventitious roots while non transgenic shoots turn brownish at the stem cut.

OUR RESULTS: Over 70\% of the regenerated shoots from all selected landraces were positive for the rooting test (Table 3). GUS assay was also performed to confirm the transgenic status of regenerated plantlets positive in the rooting test (Figure 5).

\section{Southern blot analysis}

Southern Blot analysis is performed to determine the number of independent insertion events for each plantlet positive in the rooting test. This molecular analysis is carried out following previously described methods $[25,26]$ :

1. Extract the cassava genomic DNA from freezedried leaves.

2. Digest $10 \mu \mathrm{g}$ DNA with 25000 units of HindIII or 20000 units PstI overnight and run the digested DNA in $1 \%$ agarose gel.

3. Blot the DNA onto Hybond-N+ membrane (GE Healthcare) and fix by cross-linking in a BIO-LINK UV-crosslinker.

4. Hybridize the membrane with DIG-labeled probe amplified from the hygromycin gene present in pCAMBIA1301.

Table 3 GUS assay, rooting test, and independent line percentage of the selected cassava landraces

\begin{tabular}{lccccccc}
\hline Name & Procedure & $\begin{array}{c}\text { Number of tested } \\
\text { maturing embryo }\end{array}$ & $\begin{array}{c}\text { GUS } \\
\text { Positive }\end{array}$ & $\begin{array}{c}\text { Number of } \\
\text { regenerated shoots }\end{array}$ & $\begin{array}{c}\text { Rooting } \\
\text { Test positive }\end{array}$ & $\begin{array}{c}\text { Transformation efficiency } \\
\text { GUS assay }\end{array}$ & Rooting Test \\
Independent Line
\end{tabular}

Single-step (SS) and double-step (DS) on proliferation media are reported in the procedure column. 


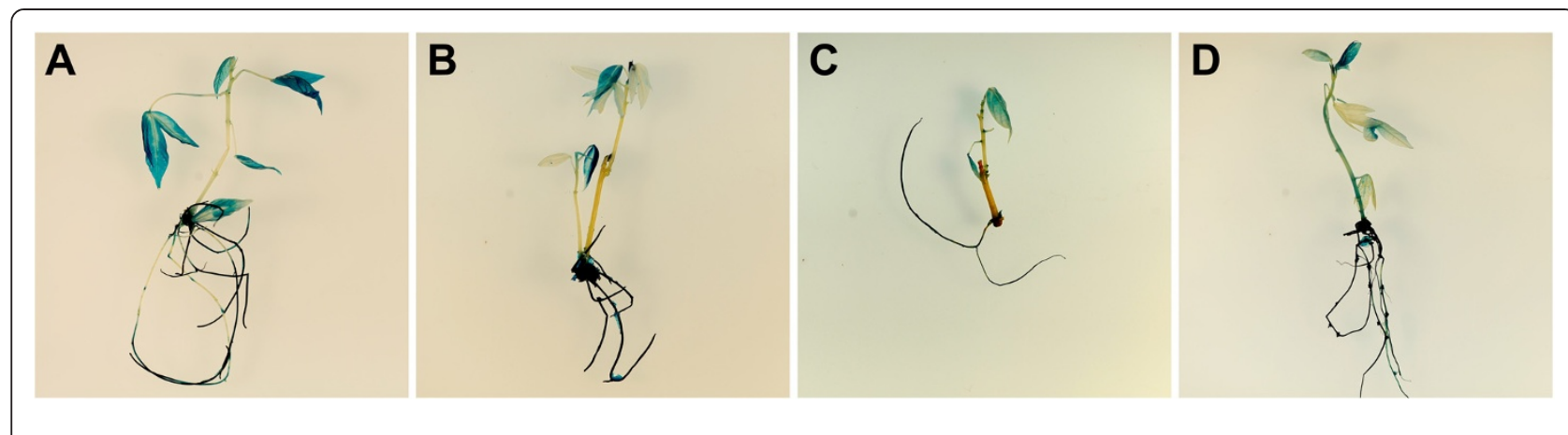

Figure 5 GUS staining of transformed cassava genotypes: (A) cv. 60444, (B) $2^{\text {nd } A g r i c, ~(C) ~ O k o-i y a w o, ~(D) ~ A b b e y-i f e . ~}$

5. Reveal presence of hybridized probes with light sensitive films.

\section{Trouble shooting}

Doubling the recovery and proliferation time on selective medium increases the probability of regenerating transgenic plantlets from the same transgenic event. In our hands, Oko-iyawo produced a lower percentage of independent transformation events (Table 3 \& Additional file 1: Figure S1). It was noticeable that the extended time on proliferation media resulted in a thick layer of FEC and therefore FEC were most probably not homogenously exposed to antibiotic selection. Thick FEC layers can increase escape rates [16] and therefore it is recommended to spread the FEC layer (Agrobacterium inoculation and co-cultivation of FEC, step 5) as thin as possible (1-2 mm thick).

The optimization of the cassava transformation protocol for farmer-preferred landraces was performed with 18 FEC clumps, which represents a limited amount of starting material. For applications requiring a large number of independent transgenic plantlets, the amount of high quality FEC clumps can be scaled up in order to produce the required number of independent transgenic lines. This is particularly important for field experiment research and product development, for which precise transgene expression levels and single integration events are needed. We routinely used between 40 and 100 FEC clumps as starting material to generate over 20 independent transgenic lines per construct. For example, we recently used the protocol described here to generate transgenic cassava Oko-iyawo lines resistant to cassava brown streak disease (CBSD) using 45 FEC clumps to generate over 20 independent transgenic lines [27].

\section{Comments}

The optimized transformation procedure for cv. 60444 [17] allowed us to establish a high-throughput transformation platform at ETH Zurich as well as transfer of this technology to African laboratories $[15,16]$. The development of a genotype-independent transformation procedure has been recognized by the cassava research community as an essential step for the adoption and deployment of transgenic cassava lines with improved traits $[7,8,15]$. Because of its robustness and efficiency, the improved transformation protocol will also be adequate for the production of transgenic events in other farmer-preferred cultivars and landraces. Adapting the protocol to maintain a high efficiency at each key step of the Agrobacterium-FEC based transformation, we demonstrated here that our method is also suitable for the production of transgenic farmer-preferred landraces. The efficiency and reliability of the adapted protocol for the production of independent transgenic events in farmer-preferred landraces is comparable to cv. 60444 and therefore is transferable to other laboratories as well. A robust transformation protocol for farmer-preferred cassava cultivars and landraces will be particularly beneficial for laboratories located in regions where cassava is used as food security and energy crop.

The optimization procedure and the protocol described here can also be used to establish the transformation technology for additional farmer- and industry-preferred cultivars in other laboratories. Our recent technology transfer activities in South Africa and Kenya demonstrated already that the protocol is robust and suitable for the production of transgenic lines from a locally grown industry-preferred cultivar [16]. Because the landraces presented in the study were selected on the basis of their CMD resistance trait, our method will be instrumental for stacking genetic and engineered traits, for which proof-ofconcept already exists.

\section{Additional file}

Additional file 1: Figure S1. Southern blot analysis of transgenic cassava plantlets. Molecular analysis of transgenic plantlets from 
(A) $2^{\text {nd }}$ Agric genotype using the double-step procedure, (B) Oko-iyawo genotype using the double-step procedure, (C) Abbey-ife genotype using the double-step procedure, (D) Oko-iyawo genotype using the single-step procedure. Independent lines are indicated by red labels. Southern blot has been repeated with Pstl restriction for lines with similar integration pattern to confirm independent integration event (data not shown).

\section{Competing interests}

The authors declare that they have no competing interests.

\section{Authors' contributions}

$\mathrm{HV}$ and IMZ designed the experiments; IMZ and KS undertook experimental works; HV and IMZ wrote the manuscript; WG edited the manuscript. All authors read and approved the final manuscript.

\section{Acknowledgements}

We thank Michael Niklaus (ETH Zurich) for technical support and Ivan Ingelbrecht (IITA-lbadan) for kindly providing the cassava landraces. We also thank ETH Zurich for research support and the Federal Commission for Scholarships for Foreign Students (FCS) Switzerland for a Swiss Confederation Scholarship to IMZ.

Received: 30 March 2012 Accepted: 20 June 2012

Published: 11 July 2012

\section{References}

1. Cassava for food and energy security. http://www.fao.org/newsroom/en/ news/2008/1000899/index.html.

2. Lobell DB, Burke MB, Tebaldi C, Mastrandrea MD, Falcon WP, Naylor RL: Prioritizing climate change adaptation needs for food security in 2030. Science 2008, 319:607-610.

3. Balat M, Balat H: Recent trends in global production and utilization of bio-ethanol fuel. Appl Energ 2009, 86:2273-2282.

4. Jansson C, Westerbergh A, Zhang JM, Hu XW, Sun CX: Cassava, a potential biofuel crop in the People's Republic of China. Appl Energ 2009, 86:595-S99.

5. Ceballos H, Iglesias CA, Perez JC, Dixon AGO: Cassava breeding: opportunities and challenges. Plant Mol Biol 2004, 56:503-516.

6. Rudi N, Norton GW, Alwang J, Asumugha G: Economic impact analysis of marker-assisted breeding for resistance to pests and post- harvest deterioration in cassava. Afr J Agr Res Econ 2010, 4:110-122.

7. Sayre R, Beeching JR, Cahoon EB, Egesi C, Fauquet C, Fellman J, Fregene M, Gruissem W, Mallowa S, Manary M, et al: The BioCassava Plus Program: Biofortification of Cassava for Sub-Saharan Africa. Annu Rev Plant Biol 2011, 62:251-272.

8. Liu J, Zheng Q, Ma Q, Gadidasu KK, Zhang P: Cassava genetic transformation and its application in breeding. J Integr Plant Biol 2011, 53:552-569.

9. Zhang P, Wang WQ, Zhang GL, Kaminek M, Dobrev P, Xu J, Gruissem W: Senescence-Inducible Expression of Isopentenyl Transferase Extends Leaf Life, Increases Drought Stress Resistance and Alters Cytokinin Metabolism in Cassava. J Integr Plant Biol 2010, 52:653-669.

10. Vanderschuren H, Alder A, Zhang P, Gruissem W: Dose-dependent RNAi-mediated geminivirus resistance in the tropical root crop cassava. Plant Mol Biol 2009, 70:265-272.

11. Welsch R, Arango J, Bar C, Salazar B, Al-Babili S, Beltran J, Chavarriaga P, Ceballos H, Tohme J, Beyer P: Provitamin A accumulation in cassava (Manihot esculenta) roots driven by a single nucleotide polymorphism in a phytoene synthase gene. Plant Cell 2010, 22:3348-3356.

12. Koehorst-van Putten HJ, Sudarmonowati E, Herman M, Pereira-Bertram IJ, Wolters AM, Meima H, de Vetten N, Raemakers CJ, Visser RG: Field testing and exploitation of genetically modified cassava with low-amylose or amylose-free starch in Indonesia. Transgenic Res 2012, 21:39-50.

13. Abhary M, Siritunga D, Stevens G, Taylor NJ, Fauquet CM: Transgenic biofortification of the starchy staple cassava (Manihot esculenta) generates a novel sink for protein. PLoS One 2011, 6:e16256.

14. Masona MV, Taylor NJ, Robertson Al, Fauquet CM: Transferring a cassava (Manihot esculenta Crantz) genetic engineering capability to the African environment: Progress and prospects. Euphytica 2001, 120:43-48.
15. Bull SE, Ndunguru J, Gruissem W, Beeching JR, Vanderschuren H: Cassava: constraints to production and the transfer of biotechnology to African laboratories. Plant Cell Rep 2011, 30:779-787.

16. Chetty CC, Rossin CB, Gruissem W, Vanderschuren H, Rey MEC: Empowering biotechnology in southern Africa: Establishment of a robust transformation platform for the production of transgenic industrypreferred cassava. New Biotechnol J 2012. doi:10.1016/j.nbt.2012.04.006.

17. Bull SE, Owiti JA, Niklaus M, Beeching JR, Gruissem W, Vanderschuren H: Agrobacterium-mediated transformation of friable embryogenic calli and regeneration of transgenic cassava. Nat Protoc 2009, 4:1845-1854.

18. Niklaus $M$, Gruissem W, Vanderschuren H: Efficient transformation and regeneration of transgenic cassava using the neomycin phosphotransferase gene as aminoglycoside resistance marker gene. GM Crops 2011, 2:193-200.

19. Fregene M, Bernal A, Duque M, Dixon A, Tohme J: AFLP analysis of African cassava (Manihot esculenta Crantz) germplasm resistant to the cassava mosaic disease (CMD). Theor Appl Genet 2000, 100:678-685.

20. Raemakers K, Schreuder M, Pereira I, Munyikwa T, Jacobsen E, Visser R: Progress made in FEC transformation of cassava. Euphytica 2001, 120:15-24.

21. Rossin CB, Rey MEC: Effect of explant source and auxins on somatic embryogenesis of selected cassava (Manihot esculenta Crantz) cultivars. S Afr J Bot 2011, 77:59-65.

22. Raji A, Ladeinde O, Dixon A: Screening landraces for additional sources of field resistance to cassava mosaic disease and green mite for integration into the cassava improvement program. J Integr Plant Biol 2008, 50:311-318.

23. Zhang P, Gruissem W: Production of transgenic cassava (Manihot esculenta Crantz). In Transgenic Crops of the World - Essential Protocols. Edited by Curtis IS. Dordrecht: Kluwer Academic Publishers; 2004:301-319.

24. Zhang P, Puonti-Kaerlas J: PIG-mediated cassava transformation using positive and negative selection. Plant Cell Rep 2000, 19:1041-1048.

25. Vanderschuren H, Akbergenov R, Pooggin MM, Hohn T, Gruissem W, Zhang P: Transgenic cassava resistance to African cassava mosaic virus is enhanced by viral DNA-A bidirectional promoter-derived siRNAs. Plant Mol Biol 2007, 64:549-557.

26. Zhang P, Vanderschuren H, Futterer J, Gruissem W: Resistance to cassava mosaic disease in transgenic cassava expressing antisense RNAs targeting virus replication genes. Plant Biotechnol J 2005, 3:385-397.

27. Vanderschuren H, Moreno I, Bodampalli R, Zainuddin I, Gruissem W: Exploiting the combination of natural and genetically engineered resistance to DNA and RNA viruses impacting cassava production in Africa. PLoS One, in revision.

doi:10.1186/1746-4811-8-24

Cite this article as: Zainuddin et al:: Robust transformation procedure for the production of transgenic farmer-preferred cassava landraces. Plant Methods 2012 8:24.

\section{Submit your next manuscript to BioMed Central and take full advantage of:}

- Convenient online submission

- Thorough peer review

- No space constraints or color figure charges

- Immediate publication on acceptance

- Inclusion in PubMed, CAS, Scopus and Google Scholar

- Research which is freely available for redistribution 